\title{
Article \\ Experimental Study on the Crushing Properties of Corn Stalks in Square Bales
}

\author{
Jie Zhang ${ }^{1,2}$, Bin Feng ${ }^{2, *}$, Xiuzhen $\mathrm{Yu}^{2}$, Chao Zhao ${ }^{2}$, Hao $\mathrm{Li}^{2}$ and Za Kan ${ }^{1, *}$ \\ 1 College of Mechanical and Electrical Engineering, Shihezi University, Shihezi 832000, China; \\ xjwszj0230@sina.com \\ 2 Institute of Agricultural Mechanization, Xinjiang Academy of Agricultural Sciences, Urumqi 830000, China; \\ yxzshz@126.com (X.Y.); xjwszhaochao@sina.com (C.Z.); li_hao818@126.com (H.L.) \\ * Correspondence: xjwsfb@sina.com (B.F.); kz_mac@shzu.edu.cn (Z.K.); Tel.: +86-130-3132-1373 (Z.K.)
}

check for updates

Citation: Zhang, J.; Feng, B.; Yu, X.; Zhao, C.; Li, H.; Kan, Z. Experimental Study on the Crushing Properties of Corn Stalks in Square Bales. Processes 2022, 10, 168. https://doi.org/ $10.3390 /$ pr10010168

Academic Editors: Tiancheng Mu and Zhimin Xue

Received: 1 December 2021

Accepted: 4 January 2022

Published: 16 January 2022

Publisher's Note: MDPI stays neutral with regard to jurisdictional claims in published maps and institutional affiliations.

Copyright: (C) 2022 by the authors. Licensee MDPI, Basel, Switzerland. This article is an open access article distributed under the terms and conditions of the Creative Commons Attribution (CC BY) license (https:// creativecommons.org/licenses/by/ $4.0 /)$.

\begin{abstract}
With the development of straw baling mechanization technology, straw is stored in the form of square baling or round baling. At present, hammer mill or the guilt-cutting and rubbing combined mill is widely used to crush square bales of straw. These two kinds of crushing equipment have disadvantages such as low productivity, large power consumption, and poor crushing effect. This paper aims to study and analyze the crushing characteristics of square baled straw after unbaling, and lay a theoretical foundation for the later research and development of a special square baled straw crusher with high productivity, low power consumption, good crushing effect, and the simulation of the square baled corn straw crushing process. For this purpose, this study carried out a corn bale crushing experiment on the Instron 8801 fatigue test machine, and studied the effects of blade angle, water content and loading speed on corn bale crushing force through the response surface method. Test results showed that the crushing process includes the compression stage and shearing stage; in terms of single factor effect, with the increase in water content and blade angle, the crushing force of the corn bale increased, but the loading speed had no significant effect on the crushing force of the corn bale. In terms of interaction effect, there was interaction effect between moisture content and blade inclination angle, when moisture content was 10\%, with the increase in blade inclination angle, the incremental speed of the crushing force also increased gradually. When the blade inclination angle was $10^{\circ}$, with the increase in moisture content, the incremental speed of the crushing force also increased, and the interaction effect of them jointly acted on the crushing force of the corn bales.
\end{abstract}

Keywords: square bale corn stalks; crushing force; blade inclination angle; moisture content

\section{Introduction}

Crop stalk is an important product in agricultural production, and there are over 2 billion tons of stalks produced in the world [1]. China has abundant corn stalk resources, taking up $1 / 3$ of the total stalk resources of the country [2,3]. Corn stalk cannot only be used to provide industrial raw materials for building boards and papermaking [4,5], but also be used to provide resources for combustion and power generation, and serve as an important resource of silage [6-8].

In order to optimize the parameters of corn stalk crushers and provide guidance to production and processing, to enhance the production efficiency of corn stalk crushers, it is necessary to analyze the force properties of corn stalks. At present, a great deal of research has been performed on shear properties of stalks. In order to destroy the pupae in hay bales, A. Opoku et al. [9] conducted research on the destruction characteristics of hay bales with different moisture content. The results showed that increasing the breaking speed can increase the breaking force and breaking strength; as the moisture content increased, the breaking force and the crushing strength gradually decreased. The average maximum crushing force was $1.457 \sim 2.358 \mathrm{kN}$, and the average maximum crushing strength was 
11.24 19.52 MPa. I. Aydın et al. [10] studied the shearing force and shearing energy, and explored the influence law of cotton stalk parts and moisture content on shear properties. Bahram Hoseinzadeh et al. [11] studied the shearing properties and bending properties of oilseed rape under different moisture contents, and obtained that, with the increase in moisture content, the shearing stress, bending stress and the Young's modulus were all on the decrease. The results showed that the shearing force, water content, maximum shearing stress and specific shearing energy were $73 \mathrm{~N}, 72 \%, 4.94 \mathrm{MPa}$ and $0.069 \mathrm{~J} \mathrm{~mm}^{-2}$ in section $\mathrm{A}$, respectively; and $121 \mathrm{~N}, 64.8 \%, 4.65 \mathrm{MPa}$ and $0.078 \mathrm{~J} \mathrm{~mm}^{-2}$ in section $\mathrm{B}$, respectively. In order to provide a theoretical basis for grape harvesting machinery, Michele Carrara et al. [12] studied the destructive force of grape branches and the connection force between grapes and stems during different harvest periods. The results showed that the longer the growth days, the greater the destructive strength and connection force, and the greater the difference between the destructive force and connection force during day and night, the minimum failure strength was $5.45 \mathrm{~N}$, and the minimum connection force was $1.41 \mathrm{~N}$. Chen et al. [13] studied the shearing properties of soybean stalks in the aspects of moisture content, shear angle and blade angle, and adopted a response surface method to determine the optimal parameters for the moisture content, shear angle and blade angle of soybean stalks. The experimental results showed that the shearing angle had the greatest influence on the shearing effect of soybean straw, while the blade angle had the least influence. F. Göksel Pekitkan et al. [14] studied the destructive force and energy consumption characteristics of grape branches using the knife shape, cutting angle, and loading speed as experimental factors. The results showed that the blade shape had a significant effect on the destructive force and energy consumption, and the serrated blade has the best effect, with the smallest destructive force, destructive strength, and destructive energy, which were $346.4 \mathrm{~N}, 6.887 \mathrm{MPa}$, and $2.398 \mathrm{~J}$, respectively. The cutting angle of the tool increased from $0^{\circ}$ to $40^{\circ}$, the destructive force and destructive energy were gradually reduced, and the cutting speed had no significant effect on the result. Chen et al. [15] studied the tensile and shearing characteristics of corn straw husk by designing the quadratic orthogonal rotation combination test, and concluded that high water content and appropriate blade speed were conducive to improving the core separation efficiency of corn husk. Loay A et al. [16] studied the elastic modulus of corn stalk under three loading modes, and the results showed that the elastic modulus values obtained by the three modes were approximately equal, with the modulus values ranging from 6 to $16 \mathrm{GPa}$, and the elastic modulus between nodes was significantly higher than that between nodes. The bending test had the lowest bending strength, and tensile test had a higher accuracy of elastic modulus. However, the sample preparation time was longer. Raghami., N et al. [17] studied the effects of three kinds of wheat on the shearing characteristics of wheat straw at different knife angles, four moisture contents, and three pendulum shearing speeds. The results showed that: variety, knife angle, moisture content and shearing rate had significant effects on shearing energy $(p<0.01)$. Shearing energy decreased with the decrease in water content and blade angle, and increased with the increase in shear rate. The wheat variety Kohdasht had the greatest shearing energy. The shearing energy was the smallest when the blade inclination angle was $25^{\circ}$ and $30^{\circ}$.

Through the above discussion, it was found that domestic and foreign scholars conducted a lot of research on stalk mechanics. The research factors were mostly moisture content, position, shear angle, etc., but there were no reports on the mechanical properties of corn bale crushing. Based on the research of domestic and foreign scholars, this paper combines the characteristics of the corn bale crusher to study the influence of moisture content, knife edge inclination and loading speed on the mechanical characteristics of corn bale crushing. The special straw crusher and the simulation of the crushing process of square bales of corn stalks lay the theoretical foundation. 


\section{Materials and Methods}

\subsection{Test Materials and Sample Making}

The test used corn stalks for baling after harvesting the Yinyu No.10 corn in Shihezi, Xinjiang Uygur Autonomous Region, China in October 2020. Corn bales at different locations in the field were selected as research objects by a five-point sampling method, five samples were taken from each point, and the measurement was repeated three times, and the average value of each physical characteristic of corn bales was obtained as follows: $90 \times 45 \times 38 \mathrm{~cm}$ (length $\times$ width $\times$ height), moisture content was $12.5 \%$, weight was $14,885 \mathrm{~g}$, and bale density was $0.09672 \mathrm{~g} / \mathrm{cm}^{3}$. Figure 1 shows the Instron fatigue testing machine. As shown in Figure 1A, the equipment had a maximum load of $100 \mathrm{kN}$, a load accuracy of $\pm 0.005 \%$, and a maximum stroke of $75 \mathrm{~mm}$. The relevant experiments were completed by force or displacement control. The equipment was equipped with a three-point bending fixture, a compression fixture, and a tensile fixture. There was no tool specifically for the material crushing experiment. Therefore, the tool in the corn bale crusher was selected as the experimental tool. As shown in Figure 1B, the tool had a thickness of $8 \mathrm{~mm}$ and a length of $220 \mathrm{~mm}$. It had two cutting edges. This experiment only studies the crushing characteristics of the lower cutting edge on the corn bale. The tool was welded to the main shaft through the upper arc. The rotation of the spindle drove the rotation of the tool. Due to the characteristics of the clamp of the system, it cannot test the whole corn bale; therefore, it was necessary to fabricate a new sample based on the bale density and length of blades. In sample making, an $80 \times 80 \times 80 \mathrm{~mm}$ square tube was used to place sample corn bales. First, the original corn bale was untied, and the required corn stalks in line with the original density $0.09672 \mathrm{~g} / \mathrm{cm}^{3}$ and size of the square tube were weighed, then the weighed corn stalks were adjusted to the designated moisture content, at last, the corn stalks were placed into the square tube, and the sample making process is shown in Figure 2.

As water content was the main research factor in this experiment, the ASABE water content testing standard [18] and water content regulation method [19] were adopted in this paper to obtain different water contents of corn bales, among which Equation (1) was the calculation method of water content.

$$
x=\frac{G_{1}-G_{2}}{G_{1}} \times 100 \%
$$

where $x$ was real-time moisture content of selected sample, $\%$.

$G_{1}$ was the initial weight of selected sample, $g$.

$G_{2}$ was the weight of selected sample after drying for a period of time, $g$.

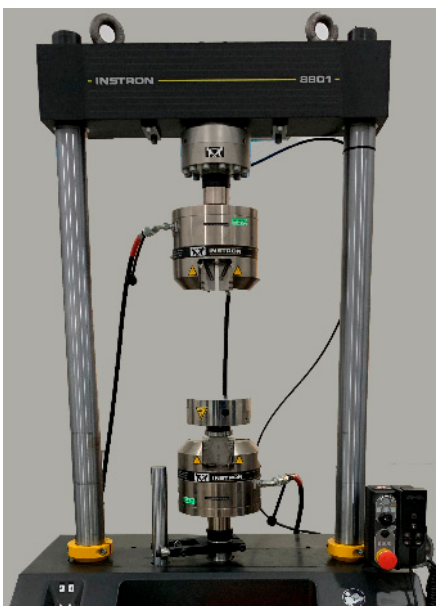

(A)

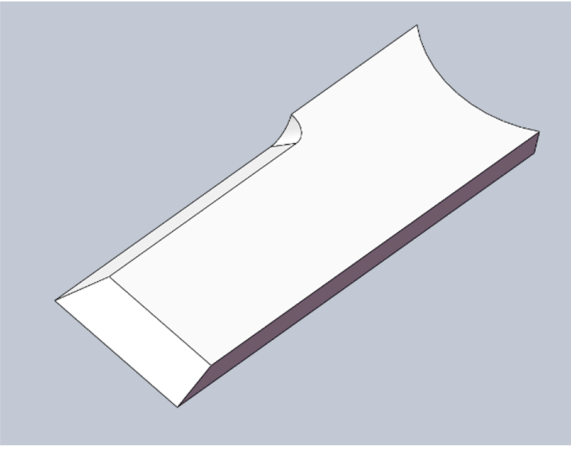

(B)

Figure 1. Experimental apparatus. (A) Instron 8801 fatigue testing system; (B) Broken tool. 


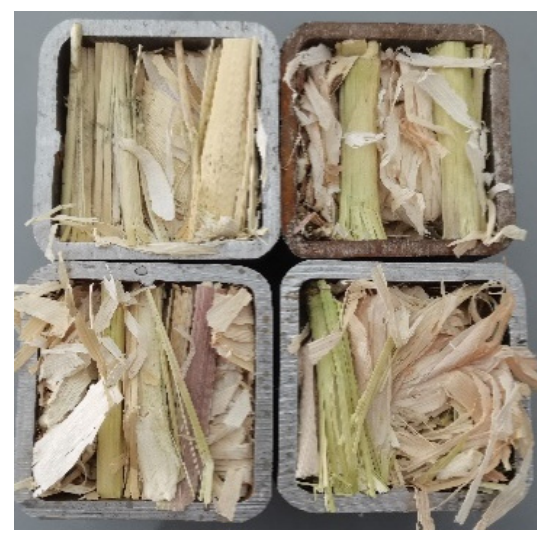

Figure 2. Sample corn bales.

\subsection{Test Method}

In this test, the Instron 8801 fatigue testing machine was used to clamp the crushing knife through the tensile upper clamp. The shape was the tool used in the corn bale crusher. In the test, the cutting edge inclination angle of the shearing knife was changed at $10^{\circ}, 30^{\circ}$, and $50^{\circ}$, the corn bale sample was placed under the lower support plate of the compression fixture. A PC was used to change the loading rate of the shearing test, after the test, the PC could draw the curves for shearing displacement and shearing force.

By taking moisture content $\mathrm{A}$, blade inclination angle $\mathrm{B}$, loading speed $\mathrm{C}$ as test factors, and the test design software Design Expert was used to design a three-factor and three-level response surface test based on the factors above, to further study the influence of the three factors on the single factor of crushing force and their interactive effect. The coded values and true values of in the test scheme were shown in Table 1, and the final test order and test data were shown in Table 2.

Table 1. Coded values and true values of the test scheme.

\begin{tabular}{cccc}
\hline \multirow{2}{*}{ Coded Values } & \multicolumn{2}{c}{ True Values } \\
\cline { 2 - 4 } & A: Moisture Content (\%) & B: Blade Inclination Angle $\left({ }^{\circ}\right)$ & C: Loading Speed (mm/min) \\
\hline-1 & 10 & 10 & 20 \\
0 & 30 & 30 & 40 \\
1 & 50 & 50 & 60 \\
\hline
\end{tabular}

Table 2. Result of corn bale sample crushing test.

\begin{tabular}{ccccc}
\hline No. & Moisture Content A & Blade Angle B & Loading Speed C & Crushing Force (N) \\
\hline 1 & 10 & 10 & 40 & 489.75 \\
2 & 10 & 30 & 60 & 802.80 \\
3 & 10 & 30 & 20 & 840.52 \\
4 & 10 & 50 & 40 & 1162.40 \\
5 & 30 & 30 & 20 & 1561.15 \\
6 & 30 & 10 & 60 & 942.00 \\
7 & 30 & 50 & 40 & 2088.15 \\
8 & 30 & 30 & 40 & 1552.30 \\
9 & 30 & 30 & 20 & 1532.52 \\
10 & 30 & 50 & 40 & 1726.10 \\
11 & 30 & 30 & 60 & 1552.65 \\
12 & 30 & 30 & 20 & 1306.25 \\
14 & 30 & 10 & 40 & 994.50 \\
& 50 & 30 & & 2087.65 \\
\end{tabular}


Table 2. Cont.

\begin{tabular}{ccccc}
\hline No. & Moisture Content A & Blade Angle B & Loading Speed C & Crushing Force (N) \\
\hline 16 & 50 & 10 & 40 & 1374.72 \\
17 & 50 & 30 & 60 & 2004.60 \\
\hline
\end{tabular}

\section{Results and Analysis}

\subsection{Analysis of the Crushing Curve}

The load-displacement curve for the corn bale samples were obtained through the test scheme above, as was shown in Figure 3. The crushing test curve can be divided into two stages: compression area I and shearing area II. During area I, the load increased from point $A$ to point $B$, in which the cutter compresses the corn bale samples and the increasing speed of load was relatively slow. When the cutter compresses the corn bale samples to the utmost degree, it went to the area II, in which the cutter could destroy corn stalks and cut into the corn bale samples to overcome the friction within the corn stalks and the load increased linearly. It can be obtained from the curve of load displacement that, in the process of crushing corn bales, the load on the bales was mainly composed of compression to corn stalks, shearing force on the corn bales, and the friction with in the corn stalks.

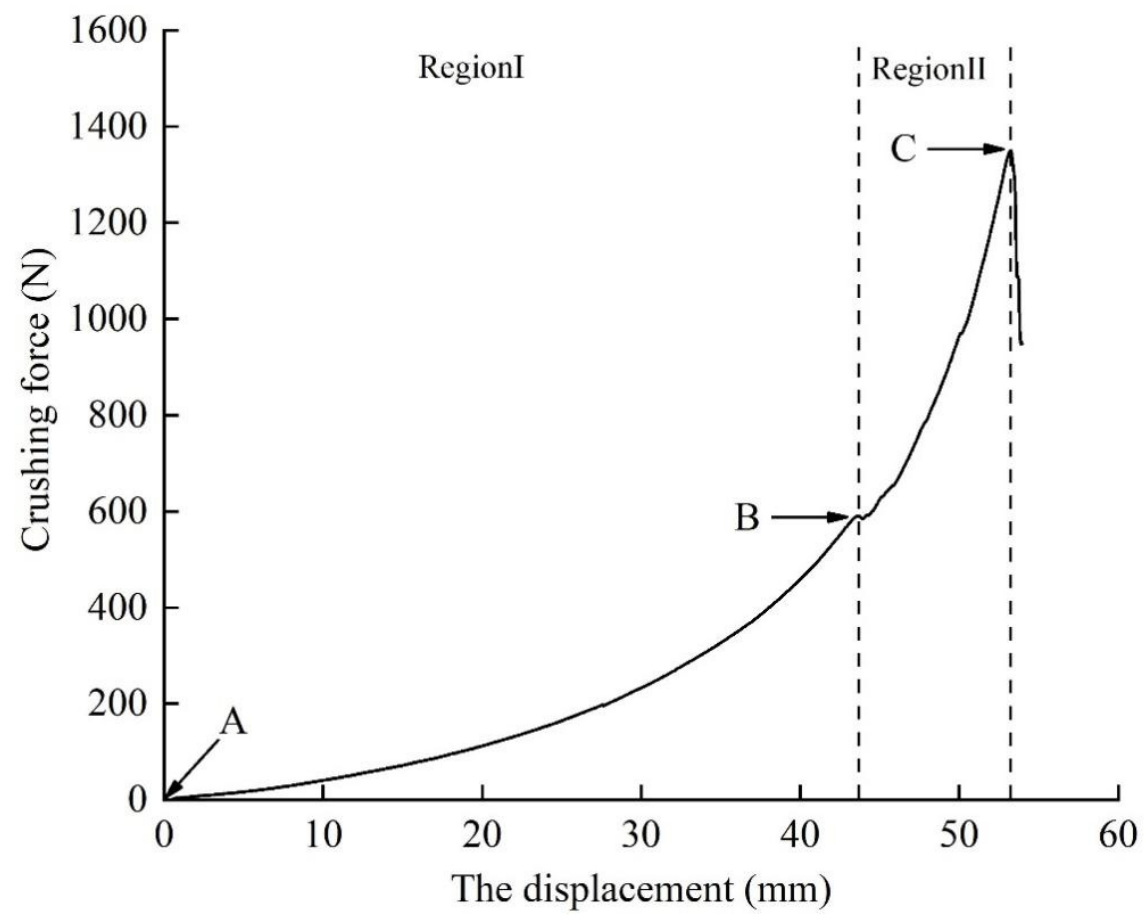

Figure 3. Curve of crushing force and displacement.

\subsection{Establishment of the Relation Model for Test Factors and Crushing Force}

Complete the experiments according to the experimental sequence in Table 2, and the data obtained were shown in Table 2. After analyzing the crushing test results in Table 2, a multi-nominal regression equation for the monomial coefficient, interactive term, and quadratic term of moisture content $\mathrm{A}$, blade inclination angle $\mathrm{B}$, and the loading speed on the crushing force was obtained, and a variance analysis was carried out on them, the equation and the variance analysis results were shown in Table 3.

It can be obtained by analyzing Table 3 that the lack-of-fit of the model $(p>0.1)$ was not significant, indicating that other factors had no effect on the test. The determination coefficient of the model was $\mathrm{R}^{2}=0.9795$, the signal-to-noise ratio $=23.09$, and the coefficient of variation in $Y(C . V)=9.04 \%$, indicating that the degree of agreement and credibility was high, and the model was established. 
Table 3. Polynomial equation and variance analysis results between the crushing force and test factors.

\begin{tabular}{|c|c|c|c|}
\hline \multirow{2}{*}{ Term of a Polynomial } & \multicolumn{3}{|c|}{ Crushing Force } \\
\hline & Sum of Squares & $F$ Value & $p$ Value \\
\hline Model & $5.95 \times 10^{6}$ & 37.19 & $<0.0001^{* * *}$ \\
\hline Moisture content A & $3.41 \times 10^{6}$ & 191.68 & $<0.0001^{* * *}$ \\
\hline Blade angle B & $2.23 \times 10^{6}$ & 125.55 & $<0.0001^{* * *}$ \\
\hline Loading speed C & $10,788.34$ & 0.6067 & $0.4616^{\mathrm{NS}}$ \\
\hline $\mathrm{AB}$ & $2.52 \times 10^{6}$ & 14.15 & $0.0071^{* * *}$ \\
\hline $\mathrm{AC}$ & 513.70 & 0.0289 & 0.8698 NS \\
\hline $\mathrm{BC}$ & $23,955.30$ & 1.35 & 0.2838 NS \\
\hline $\mathrm{A}^{2}$ & 223.26 & 0.0126 & 0.9139 NS \\
\hline $\mathrm{B}^{2}$ & 516.61 & 0.0291 & $0.8695^{\mathrm{NS}}$ \\
\hline$C^{2}$ & $23,283.76$ & 1.31 & 0.2901 NS \\
\hline $\begin{array}{l}\text { Determination } \\
\text { coefficient } R^{2}\end{array}$ & 0.9795 & & \\
\hline Signal-to-noise ratio & 23.09 & & \\
\hline C.V (\%) & 9.04 & & \\
\hline Lack-of-fit & & $0.2384^{\mathrm{NS}}$ & \\
\hline
\end{tabular}

Note: ${ }^{N S}$ : insignificant influence, $p>0.10 ;{ }^{* * *}$ : means extremely significant influence, $p \leq 0.01$.

Since the model in Table 3 was significant $(p<0.01)$, the single factor, interaction term, and quadratic term in the model were analyzed, and it was concluded that in the single factor effect, the monomial coefficient term of diameter of the loading position $\mathrm{A}$ and blade angle had a significant impact on the crushing force $(p<0.01)$, while the loading speed had no effect on the crushing force $(p>0.1)$; in terms of interactive term, the interaction between the moisture content $\mathrm{A}$ and blade inclination angle $\mathrm{B}$ had a significant impact on the crushing force $(p<0.01)$, and the remaining interaction terms and quadratic terms had no effect on the crushing force $(p>0.1)$.

After analyzing test results, Equation (2) was the regression equation of true values of the crushing force $Y$ on corn bale samples affected by the test factors.

$$
\mathrm{Y}_{1}=162.27+13.87 \mathrm{~A}-1.79 \mathrm{~B}+11.75 \mathrm{C}+0.63 \mathrm{AB}-0.03 \mathrm{AC}+0.19 \mathrm{BC}+0.02 \mathrm{~A}^{2}+0.03 \mathrm{~B}^{2}
$$

\subsection{Influence of Single Factors on the Crushing Force on Corn Bale Sample}

It can be concluded from the analysis above that the single factor effect of moisture content $\mathrm{A}$ and blade inclination angle $\mathrm{C}$ had influence on the crushing force on corn bale samples, while loading speed C had no significant effect. Based on Equation (2), other factors were taken as 0 level for single factor analysis. The influence of single factors of the crushing force on corn bale samples was obtained, as was shown in Figure 4.

It can be concluded from Figure 4 that the crushing force on corn bale samples increased with the increase in moisture content. The reason is that the increase in moisture content can aggravate the compression on corn stalks in the crushing test. With the increase in compression force, and the increase in moisture content during the shearing stage, the friction between the cutter and stalks may increase, thus increasing the crushing force. With the increase in blade inclination angle, the crushing force on the corn bale samples gradually increased, and the reason was shown in Figure $5 . F_{f}$ was the friction on the cutter during shear stage, and $F$ was the load on the corn bales from the universal testing machine. As was shown in Equation (3), with the increase in blade inclination angle, $\sin \theta$ also increased, causing the increase in friction; thus, in order to damage corn bales, the universal testing machine should impose a much higher load.

$$
F_{f}=F \cdot \sin \theta
$$



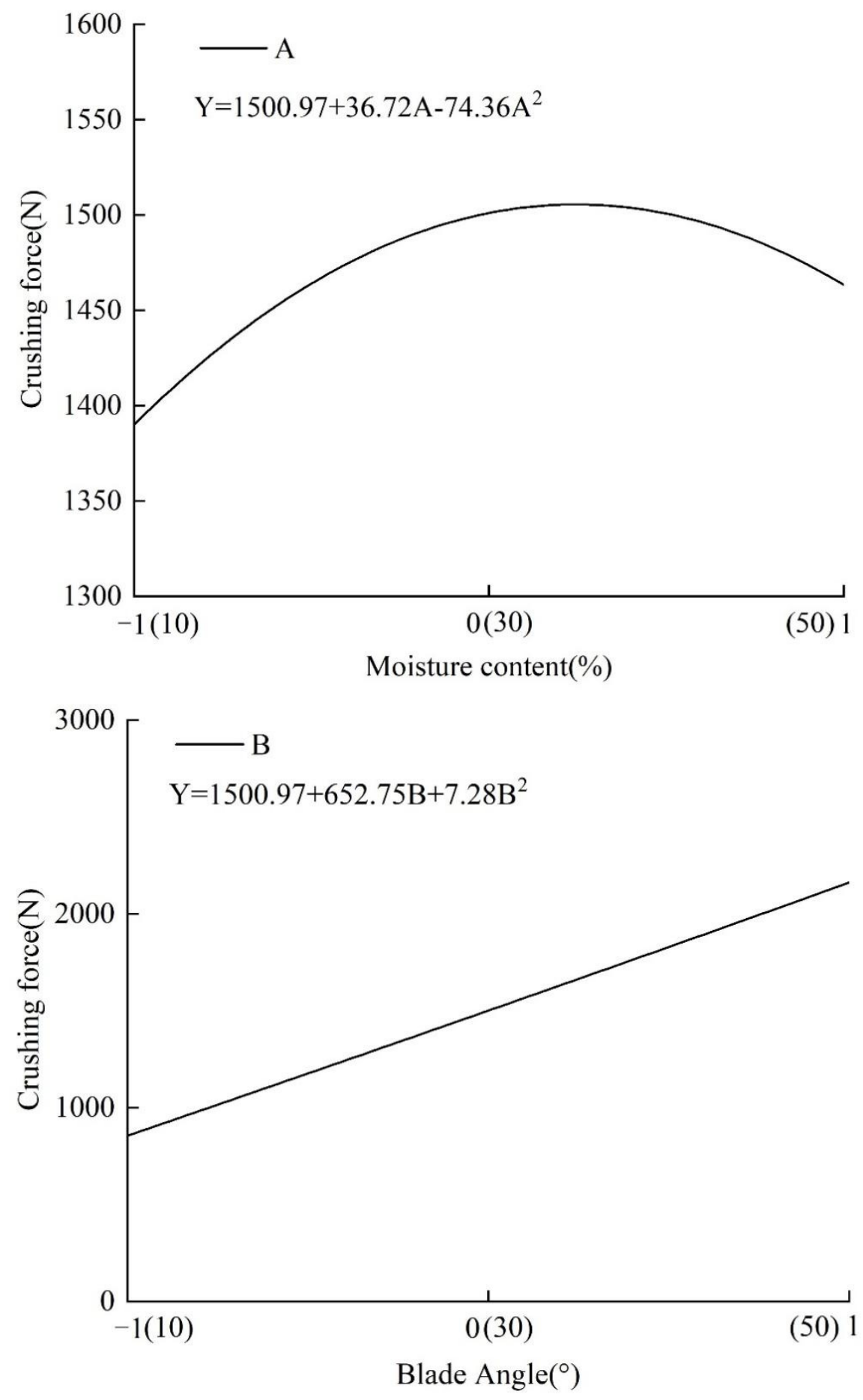

Figure 4. Cont. 


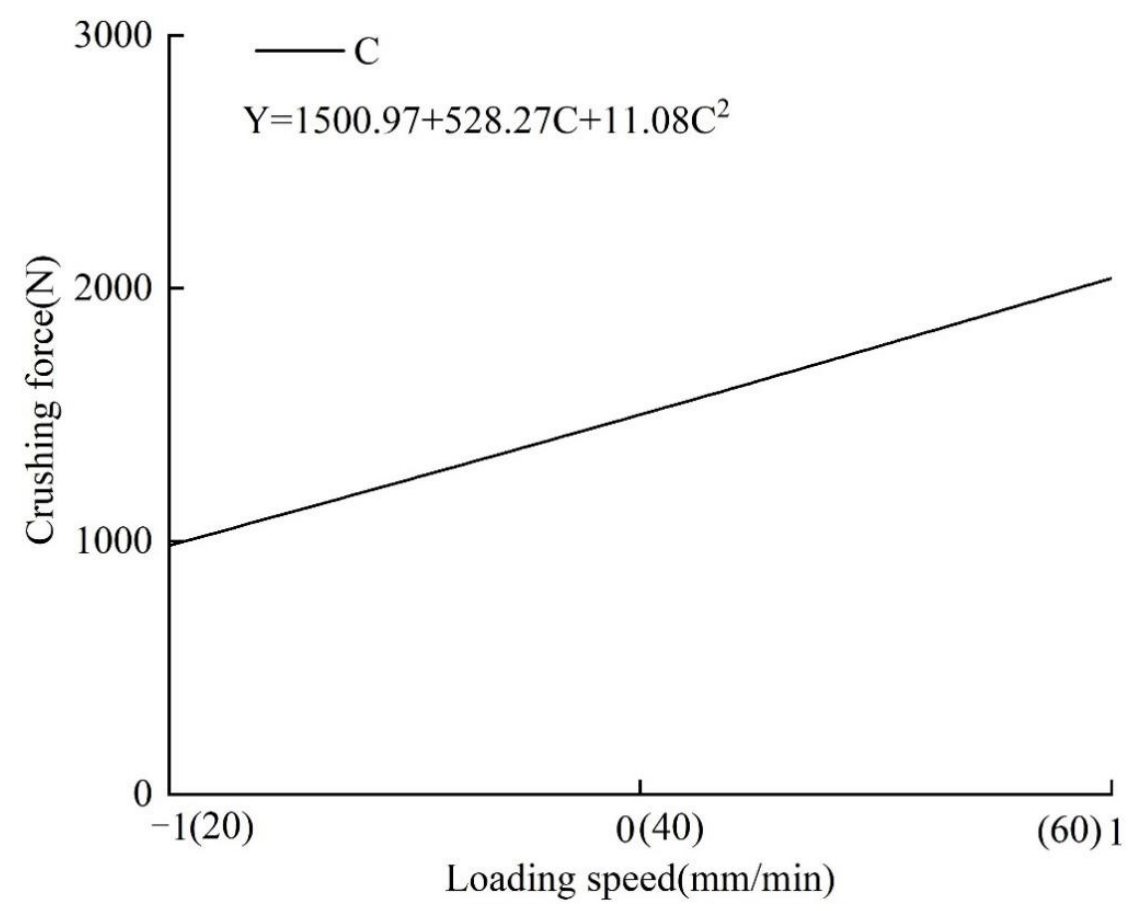

Figure 4. Influence of single factors on the shear force on corn bale samples. (A) Influence of water content on crushing force of corn bale samples. (B) Influence of blade angle on crushing force of corn bale samples. (C) Influence law of loading speed on crushing force of corn bale samples.

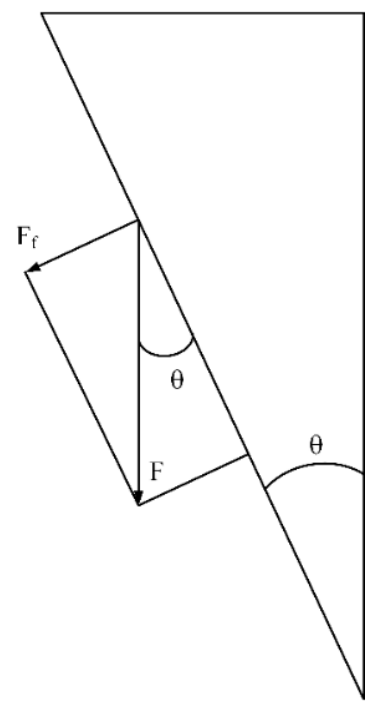

Figure 5. Force status of the cutter.

It can be concluded from Table 3 that in the two-factor interaction effect, the interaction effect between moisture content $A$ and blade inclination angle had significant influence on the crushing force on the corn bale samples, and the other three interactive effects had no influence on the crushing force.

Taking the loading speed as 0 level $(30 \mathrm{~mm} / \mathrm{min})$, the model of interaction effect on crushing force between moisture content A, blade inclination angle B, and Equation (4) showed the actual values, Figure 6 showed the influence curve of the model.

$$
\mathrm{Y}_{2}=162.27+13.87 \mathrm{~A}-1.79 \mathrm{~B}+0.63 \mathrm{AB}+0.02 \mathrm{~A}^{2}+0.03 \mathrm{~B}^{2}
$$




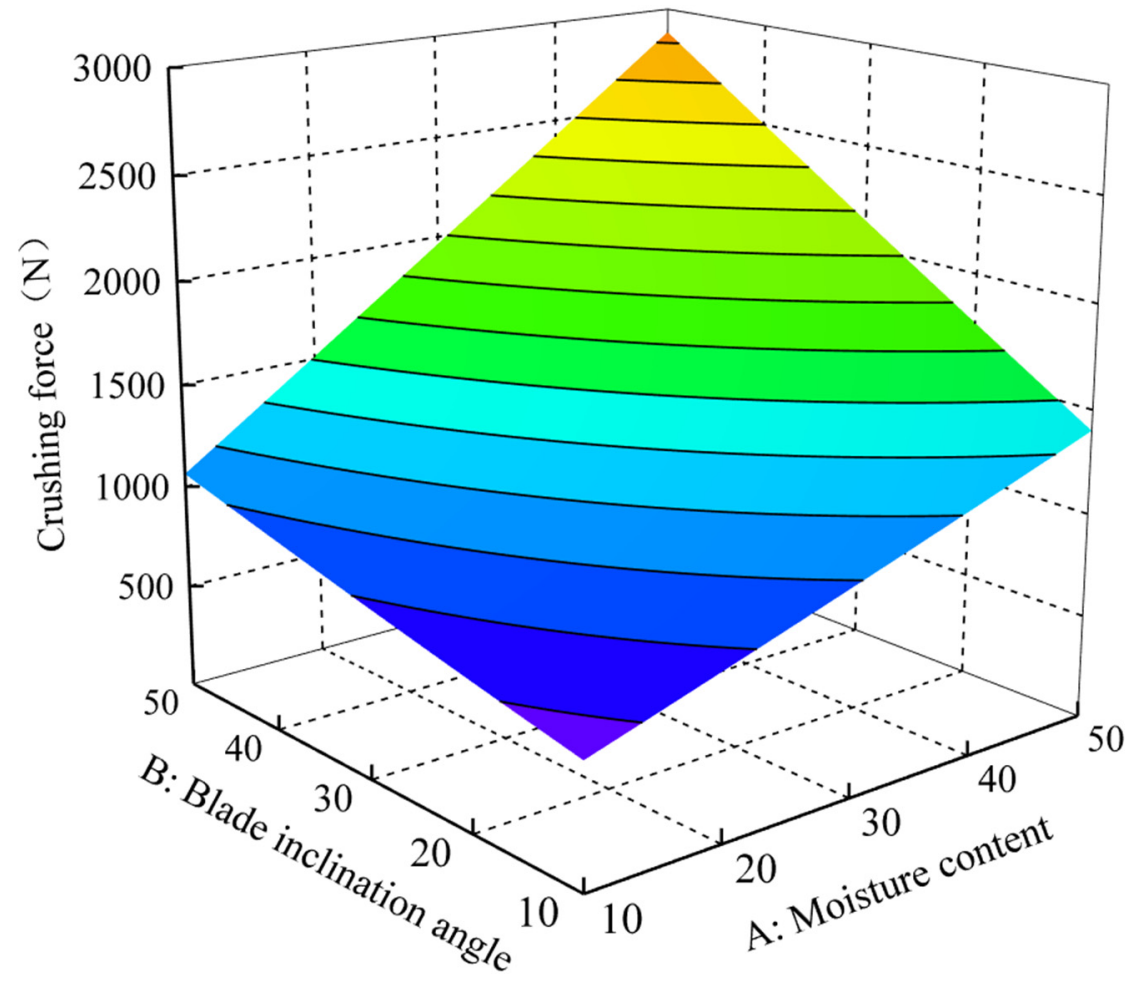

Figure 6. Interactive effect of moisture content A and blade inclination angle B on the crushing force on corn bale samples.

It can be obtained from Figure 6 that at a moisture content of $10 \%$ and blade inclination angle of $10^{\circ}$, it had the minimum crushing force; at a moisture content of $50 \%$ and blade inclination angle of $50^{\circ}$, it had the maximum crushing force. When moisture content was $10 \%$, the increased speed of crushing force with the increase in blade inclination angle was obviously lower than that when moisture content was 50\%; when the blade inclination angle was $10^{\circ}$, the increased speed of crushing force with the increase in moisture content was obviously lower than that when blade inclination angle was $50^{\circ}$, indicating that the interaction effect between them jointly influences the change in the speed of the crushing force.

\section{Conclusions}

(1) Through the crushing experiment of corn bale samples, it was concluded that the crushing process can be divided into compression stage and shearing stage, and the maximum crushing force was 3050.52N. Only after the compression stage was completed and the shearing process enters, the corn bale samples have a significant shearing effect. Therefore, in the process of corn straw baling, it should be compacted as much as possible to shorten the crushing process and improve the crushing efficiency, and the crushing force should be kept above $3050.52 \mathrm{~N}$ to achieve the best crushing effect.

(2) Through the three-factor and three-level response surface design, the influence law of moisture content, blade inclination angle, and loading speed on the crushing force on corn bale samples was explored. Among them, with the increase in water content, destructive power showed a rising trend, which was consistent with the research results of Ince, A [20]. With the increase in blade angle, the crushing force also increased gradually, which was consistent with the research results of Wang [21]. Therefore, when crushing corn sheaves, you should choose corn sheaves with a lower moisture content, and at the same time, choose a blade with a smaller blade inclination under the premise of ensuring the life of the tool. Among the interaction terms, the interaction terms of moisture content and knife edge inclination had a significant 
impact on the crushing force of the sample, and the two worked together to affect the crushing force of the corn bale sample.

(3) Through the research of this experiment, we have a more in-depth understanding of the crushing process of corn bales, and obtained the maximum force of crushing corn bales, which was a special purpose for the later development of the square bale straw with high productivity, low power consumption, and good crushing effect. The simulation process of the machine and corn bale crushing laid the theoretical foundation.

Author Contributions: Conceptualization, J.Z.; Methods, Z.K.; Software, B.F.; Verification, X.Y.; Formal analysis, C.Z.; The investigation, H.L.; Resources, Z.K.; Data Management, J.Z.; Writing the first draft, J.Z. Written by J.Z. Commentary and editor; Project Management, B.F. All authors have read and agreed to the published version of the manuscript.

Funding: Supported projects: China Agriculture Research System of MOF and MARA (CARS37); Post expert task of Meat and Sheep System in Agricultural Area of Autonomous Region (XJNQRY-G-2107).

Institutional Review Board Statement: Not applicable.

Informed Consent Statement: Not applicable.

Data Availability Statement: Not applicable.

Conflicts of Interest: The authors declare no conflict of interest. The funders had no role in the design of the study; in the collection, analyses, or interpretation of data; in the writing of the manuscript, or in the decision to publish the results.

\section{References}

1. Kronbergs, E. Mechanical strength testing of stalk materials and compacting energy evaluation. Ind. Crop. Prod. 2000, 11, 211-216. [CrossRef]

2. Han, L.; Yan, Q.; Liu, X.; Hu, J. Straw resources and their utilization in China. Trans. Chin. Soc. Agric. Eng. 2002, 18, 87-91.

3. Liu, Y. Harnessing and utilization on crop straw. Liaoning Agric. Sci. 2003, 1, 18-23.

4. Chen, H. Application of Corn Stalk Residue in Pulping and Papermaking. Master's Thesis, Qilu University of Technology, Jinan, China, 2008.

5. Wang, Q.; Shi, Y.; Li, J.; Lv, T. Optimization of corn stalk board processing technology. Trans. Chin. Soc. Agric. Mach. 2007, 38, 199-201.

6. Xi, S. Processing technology of corn stalk pellet feed. Contemp. Farm Mach. 2020, 357, 66-67.

7. Zhang, J.; Chen, L. Utilization value and processing technology of straw feed. Mod. Livest. Poult. Breed. Ind. 2020, $452,62$.

8. Zhang, P. Research advance on pathway of corn straw for feed. Farmers' Consult. 2020, 652, 144.

9. Opoku, A.; Tabil, L.G.; Talebi, S. Crushing force, deformation modulus and crushing strength of timothy hay nodal stem segments. In Proceedings of the ASABE/CSBE North Central Intersectional Meeting, Saskatoon, SK, Canada, 5-7 October 2006; American Society of Agricultural and Biological Engineers: St. Joseph, MI, USA; pp. 1-12. Available online: https: / / sci-hub.se/10.13031/2013.22373 (accessed on 25 December 2021).

10. Aydın, İ.; Arslan, S. Mechanical properties of cotton shoots for topping. Ind. Crop. Prod. 2018, 112, 396-401. [CrossRef]

11. Hoseinzadeh, B.; Shirneshan, A. Bending and shearing characteristics of Canola stem. Am.-Eurasian J. Agric. Environ. Sci. 2012, 12, 275-281.

12. Carrara, M.; Catania, P.; Pipitone, F.; Vallone, M.; Salvia, M. Assessment of the pedicel detaching and crushing forces of grape berries to determine the optimal mechanical harvesting time. J. Agric. Eng. 2007, 38, 23-37. [CrossRef]

13. Chen, J.; Zhang, L.; Tan, T. Study on the shear mechanical properties of soybean stalk. J. Hunan Agric. Univ. Nat. Sci. 2017, 43, 98-102.

14. Pekitkan, F.G.; Eliçin, A.K.; Sessiz, A. Effects of Knives Type, Cutting Angle and Loading Speed on Force and Energy Requirement of Grape Cane. J. Multidiscip. Eng. Sci. Technol. 2019, 6, 9552-9556.

15. Peng, S.; Hou, C.; Wang, J.; Chen, T.; Liu, X.; Yue, Z. Performance of anaerobic co-digestion of corn straw and algae biomass from lake Chaohu. Trans. Chin. Soc. Agric. Eng. 2012, 28, 59-65.

16. Al-Zube, L.; Sun, W.; Robertson, D.; Cook, D. The elastic modulus for maize stems. Plant Methods 2018, 14, 11. [CrossRef] [PubMed]

17. Raghami, N.; Esehaghbeygi, A.; Hoseinzadeh, B. Effect of Moisture Content, Bevel Angle and Cutting Speed on Shearing Energy of Three Wheat Varieties. World App. Sci. J. 2009, 7, 1120-1123.

18. Standards, ASABE. Moisture Measurement_Forages; American Society of Agricultural and Bio-logical Engineers: St. Joseph, MI, USA, 2008; Volume S358.2. 
19. Wen, B.; Li, Y.; Kan, Z.; Li, J.; Li, L.; Ding, L.; Li, W. Experimental research on the bending characteristics of glycyrrhiza glabra stems. Trans. ASABE 2020, 63, 1499-1506. [CrossRef]

20. İnce, A.; Uğurluay, S.; Güzel, E.; Özcan, M.T. Bending and shearing characteristics of sunflower stalk residue. Biosyst. Eng. 2005, 92, 175-181. [CrossRef]

21. Wang, H.; Wang, F.; Yang, Z.; Guo, W. Experimental study on the influencing factors of cutting resistance of sunflower stalk. J. China Agric. Univ. 2018, 5, 102-107. 